\title{
SOLID PHASE EXTRACTION OF Cd(II) AND Pb(II) IONS BY A NEW CARBOTHIOAMIDE DERIVATIVE
}

\author{
DUYGU OZDES $S^{a}$, CELAL DURAN ${ }^{b}$, HACER BAYRAK ${ }^{b}$, \\ HUSEYIN SERENCAMc, HASAN BASRI SENTURK ${ }^{b}$ \\ ${ }^{a}$ Gumushane Vocational School, Gumushane University, Gumushane 29100, Turkey \\ ${ }^{b}$ Department of Chemistry, Faculty of Sciences, Karadeniz Technical University, Trabzon 61080, Turkey \\ ${ }^{c}$ Faculty of Engineering, Department of Food Engineering, Bayburt University, Bayburt 69000, Turkey \\ (Received: January 18, 2013 - Accepted: April 17, 2013)
}

\begin{abstract}
An effective, simple, low cost and accurate sorption-spectrophotometric platform for the extractions and subsequent quantifications of $\mathrm{Cd}(\mathrm{II})$ and $\mathrm{Pb}(\mathrm{II})$ ions in food and environmental samples has been described in this dissertation. The separation and preconcentration of the analyte ions were accomplished by solid phase extraction method based on the adsorption of their N-(4-methylphenyl)-2-\{[(4-phenyl-5-pyridin-4-yl-4H-1,2,4-triazol-3-yl)thio]acetyl $\}$ hydrazinecarbothioamide (MFPTAHK) complex on Amberlite XAD-8 resin in a mini column. The developed method was systematically investigated in different set of experimental parameters that influence the separation and preconcentration of $\mathrm{Cd}(\mathrm{II})$ and $\mathrm{Pb}(\mathrm{II})$ ions. The precision of the method was determined by reproducibility studies and expressed as relative standard deviations (RSD \%) which were less than 4\% for both analyte ions. The limits of detections (LODs) for $\mathrm{Cd}(\mathrm{II})$ and $\mathrm{Pb}(\mathrm{II})$ ions based on the three times the standard deviation of the blanks $(N: 10)$ were found to be $0.31 \mu \mathrm{g} \mathrm{L}^{-1}$ and $0.86 \mu \mathrm{g} \mathrm{L}^{-1}$, respectively. The developed SPE procedure was utilized for the simultaneous extraction and determinations of $\mathrm{Cd}(\mathrm{II})$ and $\mathrm{Pb}$ (II) ions levels in rice, cracked wheat and red lentil as food samples and various water samples.
\end{abstract}

Keywords: Solid Phase Extraction, N-(4-methylphenyl)-2-\{[(4-phenyl-5-pyridin-4-yl-4H-1,2,4-triazol-3-yl)thio $]$ acetyl $\}$ hydrazinecarbothioamide, Flame atomic absorption spectrometry, Cadmium(II), Lead(II)

\section{INTRODUCTION}

Contamination of environment with heavy metals is widely increasing due to their industrial applications. Although necessary precautions are taken, pollution from industries increases day-by-day with the development of modern technology. Several heavy metals and metalloids, such as arsenic, mercury, cadmium, and lead are hazardous for living organisms when digested at above a certain concentration levels ${ }^{1}$. Environmental pollution caused by the aforementioned metals may originate from a variety of industrial applications such as electrolysis for various purposes, casting industry, surface finishing processes for metals, tannery and battery manufacturing ${ }^{1-4}$.

Lead is an extremely harmful trace element even at very small amounts. It has been proven that lead is a neurotoxin and causes adverse central and peripheral effects 5 . On the other hand, lead poisoning is a wide spread environmental health problem in the present-day situation ${ }^{6,7}$. Moreover cadmium is a toxic substance, present about in each ecosystem around the world. The half-life of this metal is in the range of 10-30 years, and its accumulation in human body causes acute and chronic metabolic disorders, such as itai-itai disease, and also affects the vital organs $4,8,9$.

Powerful analytical tools and several sensitive instrumental techniques have been developed for trace element determination as a result of rapid growth in instrumentation ${ }^{10}$. The direct application of various determination techniques is generally difficult due to the lower levels of the analyte ions than the detection limit and the complicated matrix interferences ${ }^{11}$. Therefore, in most cases a separation and preconcentration technique such as solid phase extraction $(\mathrm{SPE})^{12}$, solvent extraction ${ }^{13}$, coprecipitation $^{14}$, electrochemical deposition $^{15}$, cloud point extraction ${ }^{16}$, liquid-liquid-extraction ${ }^{17}$, ion-exchange ${ }^{18}$, and membrane filtration ${ }^{19}$ are employed prior to instrumental detections of trace metal ions.

SPE has many advantages over different sample pretreatment methods, including reduced analysis time, decreased solvent usage and disposal, cleaner extracts and high capacity and regenerability of the used adsorbent $t^{20}$. Various types of sorbents such as Amberlite resins ${ }^{21}$, activated carbon ${ }^{22}$, Diaion HP$2 \mathrm{MG}^{23}$, silica ge ${ }^{24}$, polyurethane foam ${ }^{25}$ and hydroge ${ }^{26}$ have been developed for SPE of different types of metal ions. Among these sorbents Amberlite XAD-8, used in this study, is a polyacrylic acid ester polymers with a $160 \mathrm{~m}^{2}$ $\mathrm{g}^{-1}$ surface area, $0.79 \mathrm{mg} \mathrm{g}^{-1}$ pore volume, $225 \AA$ pore diameter and $40-60 \mathrm{bead}$ mesh size, and recently, it has been used successfully as a sorbent in a few solid phase extraction studies ${ }^{27,28}$.

This paper describes an approach to develop a sensitive, safe, rapid, simple and low cost separation and preconcentration method based on SPE for the accurate determinations of $\mathrm{Cd}(\mathrm{II})$ and $\mathrm{Pb}$ (II) ions level in environmental and food samples by flame atomic absorption spectrometry (FAAS). In the presented method we have packed the mini-column with Amberlite XAD-8 as a non-polar resin, and the metal ions have been retained on the resin as their $\mathrm{N}-(4-$ methylphenyl $)-2-\{[(4-$ phenyl-5-pyridin-4-yl-4H-1,2,4triazol-3-yl)thio]acetyl hydrazinecarbothioamide (MFPTAHK) complexes. Before applying the method to sea and stream water as liquid samples and rice, cracked wheat, and red lentil as solid samples, various parameters that influence the quantitative recoveries of $\mathrm{Cd}$ (II) and $\mathrm{Pb}$ (II) ions, including $\mathrm{pH}$, eluent type, concentration and volume, quantity of ligand, sample volume, and matrix ions were investigated for optimization of the presented procedure. Also the validation of the method was evaluated by the analyte addition/recovery tests.

\section{EXPERIMENTAL}

\section{Instruments}

A Perkin Elmer AAnalyst 400 model flame atomic absorption spectrometer (Überlingen, Germany) equipped with a deuterium background corrector and hollow-cathode lamps were used to determine metal ions concentration in the aqueous solution. A digital desktop $\mathrm{pH}$ meter (Hanna Instruments Model $\mathrm{pH}$ 211, Cluj-Napoca, Romania) with glass electrode was employed to adjust the $\mathrm{pH}$ of the solutions. Milestone Ethos D closed vessel microwave system (Milestone Inc., Sorisole (BG), Italy) was operated for obtaining the clear solutions by digesting the solid samples. The instrumental parameters were chosen as recommended by the manufacturer.

\section{Reagents and solutions}

All of the chemicals, except the organic complexing agent, used in both research and routine laboratory studies, were analytical grade and obtained from Merck (Darmstadt, Germany) or Fluka (Buchs, Switzerland). The stock solutions of the selected metal ions were prepared freshly by dissolving appropriate amounts of their nitrate salts and the working solutions of the analyte ions were prepared by diluting the stock solutions of them. Dilute $\mathrm{HNO}_{3}$ and $\mathrm{NaOH}$ solutions were used for $\mathrm{pH}$ adjustments. Amberlite XAD8 resin, used as a sorbent in this study, was purchased from Sigma-Aldrich Chemicals (St. Louis, MO, USA).

The ligand, MFPTAHK, used in this study was synthesized in the organic chemistry research laboratory (Chemistry Department, Faculty of Science, Karadeniz Technical University). The detailed information for its synthesis was given in the literature ${ }^{29}$. The necessary precautions were taken when 
MFPTAHK was handled in the experiments because there was no safety data available on its usage in the literature.

\section{Sampling and pre-treatments}

Sea water (Trabzon Port, Black Sea/Turkey) and stream water (Degirmendere Stream, Trabzon/Turkey) used in this study were sampled using pre-cleaned polyethylene bottles. The water samples were filtered immediately using a nitro-cellulose membrane with a pore size of $0.45 \mu \mathrm{m}$ after being collected and stored at $4{ }^{\circ} \mathrm{C}$ until they were used. The developed SPE procedure was also applied to various solid samples; rice, cracked wheat and red lentil (Lens culinaris). The solid samples were digested with closed vessel microwave system prior to the application of the present SPE procedure. For this purpose, $1.000 \mathrm{~g}$ of rice, cracked wheat and red lentil were weighed into teflon vessels, separately and $6 \mathrm{~mL}$ of $\mathrm{HNO}_{3}$ and $2 \mathrm{~mL}$ of $\mathrm{H}_{2} \mathrm{O}_{2}$ were added into the vessels. The digestion of the solid samples by microwave radiation was performed in four steps: $6 \mathrm{~min}$ for $250 \mathrm{~W}, 6 \mathrm{~min}$ for $400 \mathrm{~W}, 6 \mathrm{~min}$ for $650 \mathrm{~W}$, and $6 \mathrm{~min}$ for $250 \mathrm{~W}$. During all these microwave radiations the pressure was kept at 45 bars, and the ventilation was $3 \mathrm{~min}$. At the end of the microwave digestion, the sample volume was completed to $100 \mathrm{~mL}$ with distilled/deionized water and then the method was applied to them.

\section{Preparation of SPE column}

The separation and preconcentration of $\mathrm{Cd}(\mathrm{II})$ and $\mathrm{Pb}$ (II) ions were achieved with a glass mini-column, having a $13 \mathrm{~cm}$ length- $1.0 \mathrm{~cm}$ diameter, porous disk and a stopcock. $250 \mathrm{mg}$ of Amberlite XAD-8 resin beads was placed into the column. The column was firstly washed with $10 \mathrm{~mL}$ of $2 \mathrm{M}$ $\mathrm{HNO}_{3}$ solution and then washed with distilled/deionized water until it is free from acid. After each cycle of preconcentration and elution experiments, the resin in the column was washed thoroughly with distilled/deionized water and then stored in distilled/deionized water for further application.

\section{General Procedure}

The solid phase extraction of $2.0 \mu \mathrm{g}$ of $\mathrm{Cd}(\mathrm{II})$ and $10.0 \mu \mathrm{g}$ of $\mathrm{Pb}$ (II) ions present in $50 \mathrm{~mL}$ of aqueous solution was carried out by adjusting the $\mathrm{pH}$ to 6.5 by adding either diluted $\mathrm{HNO}_{3}$ or $\mathrm{NaOH}$ solutions in the presence of 8.0 $\mathrm{mg}(2.0 \mathrm{~mL} 0.4 \%(\mathrm{w} / \mathrm{v}))$ of MFPTAHK. The solution was left to stand for 10 minutes in order to make sure that the formation of metal-MFPTAHK complex was completed. Then the resulting solution was passed through the column

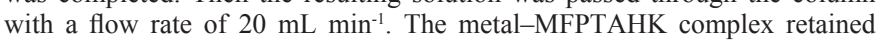
in the resin was eluted with $10 \mathrm{~mL}$ of $2.0 \mathrm{~mol} \mathrm{~L}^{-1} \mathrm{HNO}_{3}$ in acetone and the eluent was evaporated to near dryness on a hot plate. The volume of the residue was completed to $2.0 \mathrm{~mL}$ with distilled/deionized water and the solution was analyzed by FAAS.

\section{RESULTS AND DISCUSSION}

\section{Optimization parameters}

The quantitative retention of the analyte ions are strongly affected by the $\mathrm{pH}$ of the aqueous solutions. The effect of $\mathrm{pH}$ change on the separation and preconcentration of $\mathrm{Cd}(\mathrm{II})$ and $\mathrm{Pb}$ (II) ions was evaluated by changing the $\mathrm{pH}$ of the sample solutions from 2.0 to 10.0 by using either diluted $\mathrm{HNO}_{3}$ or $\mathrm{NaOH}$ solutions. As can be seen in the extraction curve of $\mathrm{Cd}(\mathrm{II})$ and $\mathrm{Pb}$ (II) ions (Fig. 1), the recovery of the analyte ions was almost constant between $\mathrm{pH} 6.0$ and 7.0 , then it decreased greatly from $\mathrm{pH} 8$ up to 10 . At $\mathrm{pH}$ values lower than 6.0 , the quantitative recoveries $(>95 \%)$ for $\mathrm{Cd}(\mathrm{II})$ and $\mathrm{Pb}(\mathrm{II})$ ions cannot be achieved hence in all subsequent experiments the $\mathrm{pH}$ value was selected as 6.5.

To obtain the optimal quantity of complexing agent for both aforementioned metal ions, the effect of quantity of MFPTAHK was examined by using different amounts of it in the range of $0-12.0 \mathrm{mg}$. It has been observed that the recovery yields of the analyte ions increased with the increase in the quantity of complexing agent, MFPTAHK, up to a certain level. The yield of the recoveries for both $\mathrm{Cd}(\mathrm{II})$ and $\mathrm{Pb}(\mathrm{II})$ ions were not quantitative $(16 \%$ and $42 \%$, respectively), when MFPTAHK was not added to the solution. As shown in Figure 2, the recovery values increased rapidly with increasing the quantity of MFPTAHK, but after reached to optimal quantity of complexing agent $(8.0$ $\mathrm{mg}(2.0 \mathrm{~mL} \% 0.4(\mathrm{w} / \mathrm{v})$ of MFPTAHK) there was no change in the recovery yields. On this basis, $8.0 \mathrm{mg}$ of MFPTAHK was added to the solutions for all subsequent works.

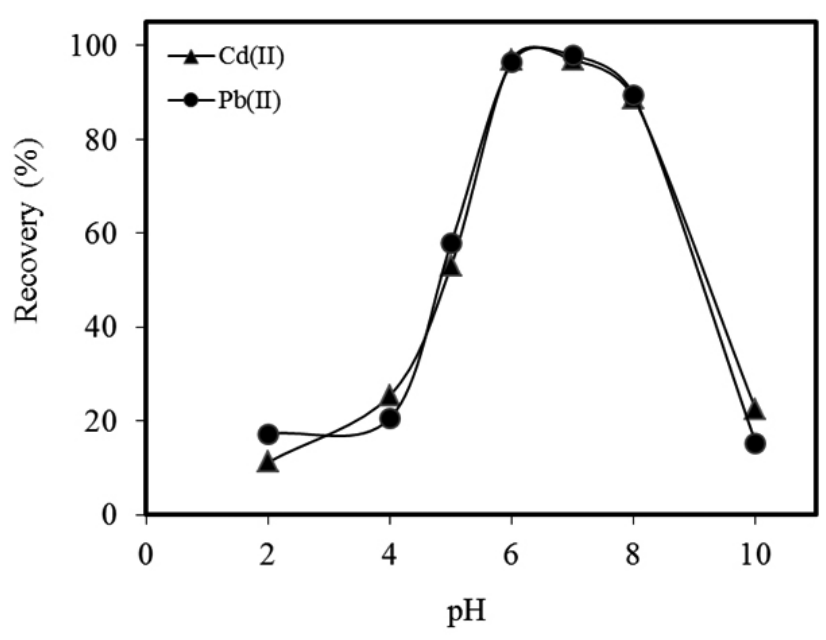

Fig.1. Effect of $\mathrm{pH}$ on the recoveries of analyte ions $(N: 3$, sample volume: $50 \mathrm{~mL}$, quantity of MFPTAHK: $8.0 \mathrm{mg}$ )

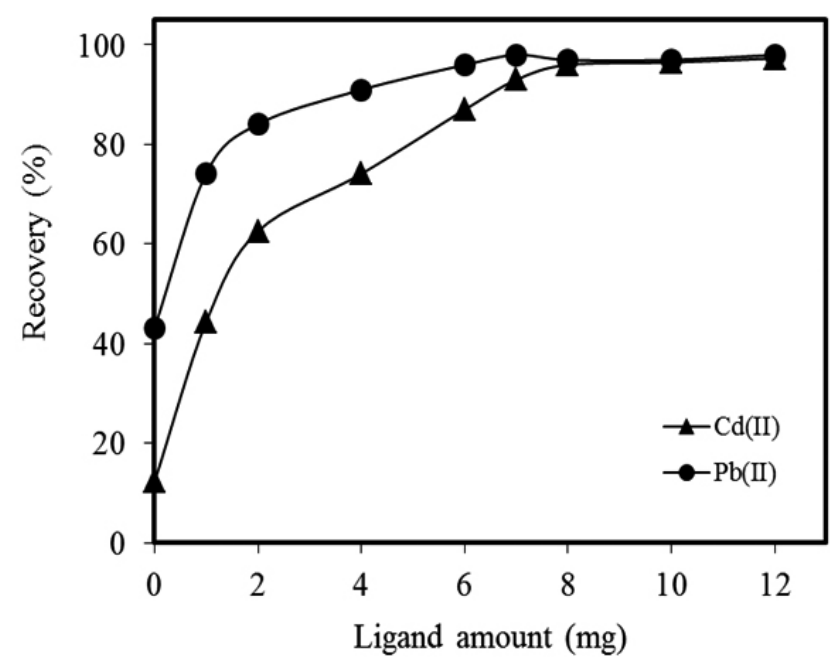

Fig.2. Effect of MFPTAHK amount on the recoveries of analyte ions $(N$ : 3, sample pH: 6.5 , sample volume: $50 \mathrm{~mL}$ )

In order to desorb the retained metal-MFPTAHK complex on Amberlite XAD-8 resin, the efficiency of the $\mathrm{HCl}$ and $\mathrm{HNO}_{3}$ solutions prepared in acetone and water were tested. The results were summarized in Table 1 . The acid solutions prepared in acetone have higher recovery efficiencies compared to the acid solutions prepared in water. Therefore $2.0 \mathrm{~mol} \mathrm{~L}^{-1} \mathrm{HNO}_{3}$ in acetone was specified as the best eluent to desorb both $\mathrm{Cd}(\mathrm{II})$ and $\mathrm{Pb}(\mathrm{II})$ ions complexes from the Amberlite XAD-8 resin. The effect of the volume of $2.0 \mathrm{~mol} \mathrm{~L}^{-1} \mathrm{HNO}$ in acetone, as eluting agent, was also investigated in the range of $2.5-15.0 \mathrm{~mL}^{3}$. As seen from Fig. 3, the quantitative recoveries were obtained after $10.0 \mathrm{~mL}$ of the eluting agent, and hence the optimum eluent volume was specified as 10.0 $\mathrm{mL}$ for all subsequent studies.

The levels of $\mathrm{Cd}(\mathrm{II})$ and $\mathrm{Pb}(\mathrm{II})$ ions in environmental real samples might be too low to be analyzed directly. The increase in the ratio of sample volume to eluent volume contributes to obtain higher preconcentration factor which provides convenience to detect the metal ions. For that purpose the influences of the sample volume on the recoveries of $\mathrm{Cd}$ (II) and $\mathrm{Pb}$ (II) ions were evaluated in the range of $50-1000 \mathrm{~mL}$ containing $2.0 \mu \mathrm{g}$ of Cd (II) and $10.0 \mu \mathrm{g}$ of Pb(II) ions under optimum conditions. The recovery values were found to be quantitative until $100 \mathrm{~mL}$ of sample volume (Fig. 4). Hence, $100 \mathrm{~mL}$ was chosen as the highest sample volume and the preconcentration factor was calculated as 50 for the investigated metal ions at optimal conditions by the ratio of the highest sample volume $(100 \mathrm{~mL})$ and the lowest final volume $(2.0 \mathrm{~mL})$. 
Table 1: The influences of eluent type on the recovery of analyte ions ( $N$ : 3 , sample pH: 6.5 , eluent volume: $10 \mathrm{~mL}$, quantity of MFPTAHK: $8.0 \mathrm{mg}$ ).

\begin{tabular}{|ll|c|c|}
\hline \multirow{2}{*}{ Eluent Type } & \multicolumn{2}{|c|}{ Recovery (\%) } \\
\cline { 3 - 4 } & $\mathrm{Cd}(\mathrm{II})$ & $\mathrm{Pb}(\mathrm{II})$ \\
\hline $1.0 \mathrm{~mol} \mathrm{~L}^{-1}$ & $\mathrm{HCl}$ in water & $46.3 \pm 3.9$ & $89.6 \pm 4.1$ \\
\hline $1.0 \mathrm{~mol} \mathrm{~L}^{-1}$ & $\mathrm{HNO}_{3}$ in water & $57.4 \pm 2.7$ & $91.3 \pm 2.5$ \\
\hline $2.0 \mathrm{~mol} \mathrm{~L}^{-1}$ & $\mathrm{HCl}$ in water & $90.9 \pm 1.6$ & $92.8 \pm 1.7$ \\
\hline $2.0 \mathrm{~mol} \mathrm{~L}^{-1}$ & $\mathrm{HNO}_{3}$ in water & $82.2 \pm 3.1$ & $93.9 \pm 3.8$ \\
\hline $4.0 \mathrm{~mol} \mathrm{~L}^{-1}$ & $\mathrm{HCl}$ in water & $71.1 \pm 2.8$ & $81.3 \pm 2.1$ \\
\hline $4.0 \mathrm{~mol} \mathrm{~L}^{-1}$ & $\mathrm{HNO}_{3}$ in water & $86.8 \pm 3.6$ & $89.2 \pm 2.7$ \\
\hline $1.0 \mathrm{~mol} \mathrm{~L}^{-1}$ & $\mathrm{HCl}_{\text {in }}$ acetone & $59.7 \pm 0.8$ & $93.3 \pm 3.1$ \\
\hline $1.0 \mathrm{~mol} \mathrm{~L}^{-1}$ & $\mathrm{HNO}_{3}$ in acetone & $66.4 \pm 2.5$ & $95.2 \pm 2.7$ \\
\hline $2.0 \mathrm{~mol} \mathrm{~L}^{-1}$ & $\mathrm{HCl}_{\text {in }}$ acetone & $94.2 \pm 3.1$ & $96.3 \pm 3.0$ \\
\hline $2.0 \mathrm{~mol} \mathrm{~L}^{-1}$ & $\mathrm{HNO}_{3}$ in acetone & $95.3 \pm 2.7$ & $99.2 \pm 4.2$ \\
\hline $4.0 \mathrm{~mol} \mathrm{~L}^{-1}$ & $\mathrm{HCl}_{\text {in }}$ acetone & $79.3 \pm 1.1$ & $78.4 \pm 1.9$ \\
\hline $4.0 \mathrm{~mol} \mathrm{~L}^{-1}$ & $\mathrm{HNO}_{3}$ in acetone & $62.7 \pm 2.5$ & $67.2 \pm 3.3$ \\
\hline
\end{tabular}

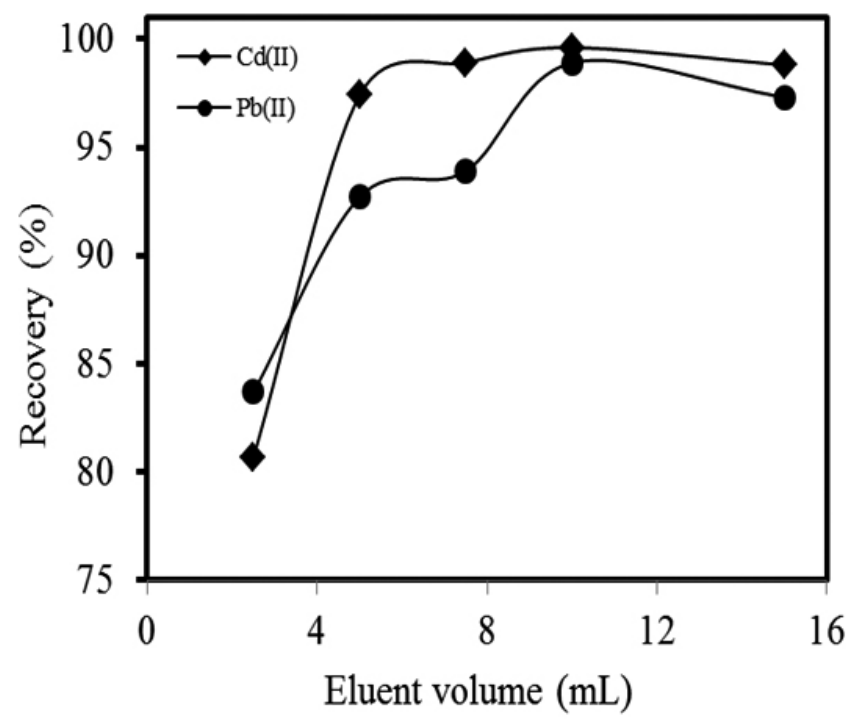

Fig.3. The influences of eluent volume on the recovery of analyte ions $\left(N\right.$ : 3, sample pH: 6.5, eluent: $2.0 \mathrm{~mol} \mathrm{~L}^{-1} \mathrm{HNO}_{3}$ in acetone, quantity of MFPTAHK: $8.0 \mathrm{mg}$ )

\section{Adsorption capacity of the resin}

The plot of Langmuir adsorption isotherm has been commonly used to calculate the capacity of the resins. Langmuir isotherm model can be fitted to data in linear form by the equation given below ${ }^{30}$ :

$$
\frac{C_{\mathrm{e}}}{q_{\mathrm{e}}}=\frac{C_{\mathrm{e}}}{q_{\max }}+\frac{1}{a_{\mathrm{L}} q_{\max }}
$$

where $q$ is the amount of metal adsorbed per unit weight of the resin ( $\mathrm{mg}$ $\mathrm{g}^{-1}$ ) at equilibrium, $C_{\mathrm{e}}$ is the equilibrium concentration of metal ions in solution $\left(\mathrm{mg} \mathrm{L}^{-1}\right), q_{\max }$ is the maximum adsorption in mono-layered adsorption systems $\left(\mathrm{mg} \mathrm{g}^{-1}\right)$, and $a$ the adsorption equilibrium constant related to the adsorption energy $\left(\mathrm{L} \mathrm{mg}^{-1}\right)$. A straight line by plotting $C_{\mathrm{e}} / q_{\mathrm{e}}$ against $C_{\mathrm{e}}$ exhibits a linear relationship, and the Langmuir constants $q_{\max }$ and $a_{\mathrm{L}}$ can be calculated from the slope and intercept of the plot, respectively.

In order to determine the Amberlite XAD- 8 resin capacity for the adsorption of $\mathrm{Cd}(\mathrm{II})$ and $\mathrm{Pb}(\mathrm{II})$ ions, different concentrations of each metal ions in the range of 50-500 $\mathrm{mg} \mathrm{L}^{-1}$ were loaded to the column filled with $250 \mathrm{mg}$ Amberlite XAD- 8 , and the adsorption amounts of $\mathrm{Cd}(\mathrm{II})$ and $\mathrm{Pb}$ (II) ions onto resin were investigated. By using the obtained results, the Langmuir isotherms were plotted (Fig. 5) and the adsorption capacity $\left(q_{\max }\right)$ of the Amberlite XAD8 resin for $\mathrm{Cd}(\mathrm{II})$ and $\mathrm{Pb}(\mathrm{II})$ ions were calculated as $3.76 \mathrm{mg} \mathrm{g}^{-1}$ and $5.07 \mathrm{mg}$ $\mathrm{g}^{-1}$ respectively.

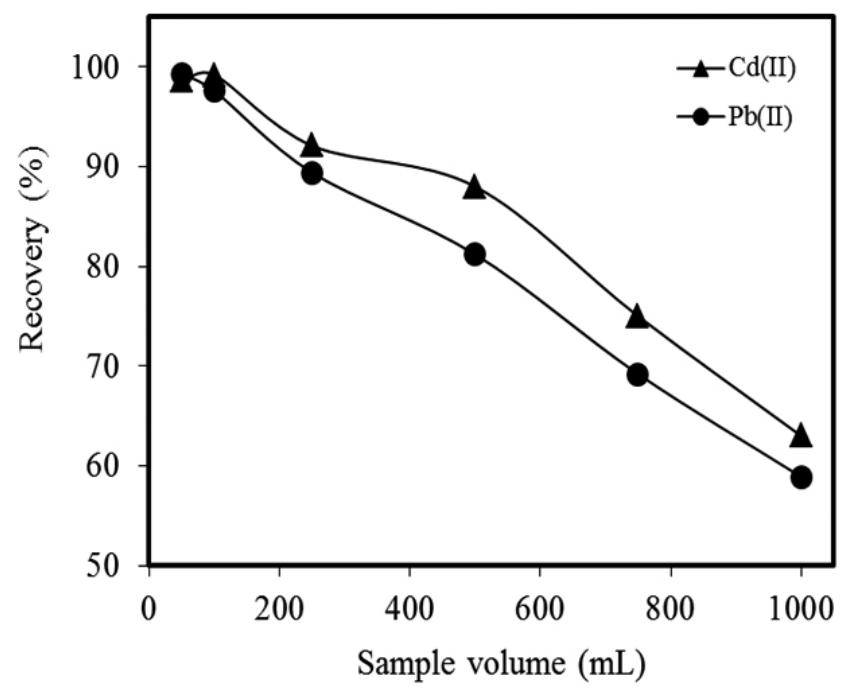

Fig.4. Effect of sample volumes on the recoveries of analyte ions $(N: 3$, sample pH: 6.5)

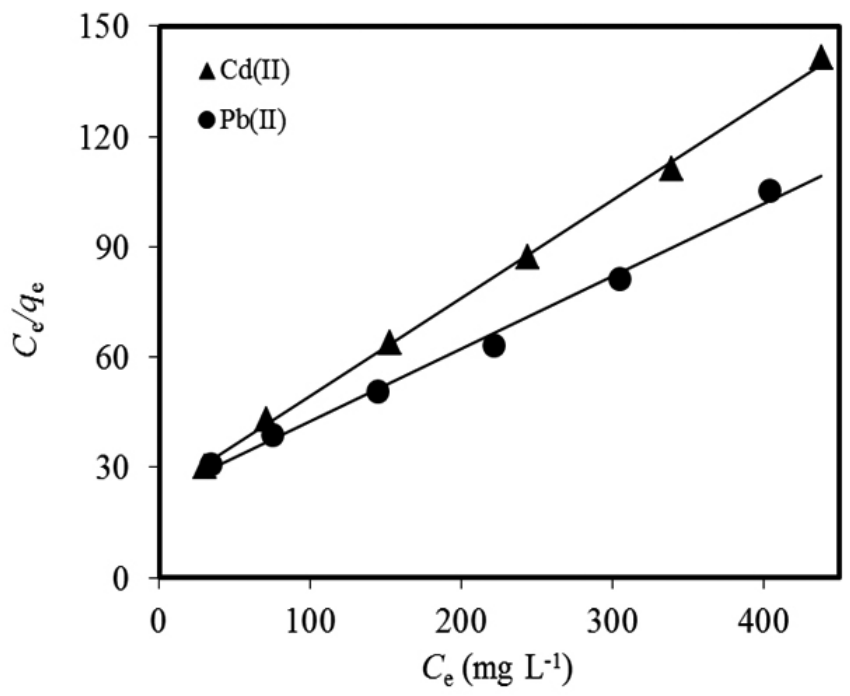

Fig.5. The plot of Langmuir adsorption isotherm

Effect of foreign ions on the recovery of analyte ions

The accurate determination of metal ions in different sample matrix is frequently problematic due to the presence of overwhelming interfering matrix components. To this end, the model solutions containing fixed amounts of $\mathrm{Cd}(\mathrm{II})$ and $\mathrm{Pb}(\mathrm{II})$ ions together with either individual matrix ions or a mixture of these ions were prepared and the developed separation and preconcentration procedure was applied to these solutions under optimal conditions. The experimental results indicated that the existence of matrix ions has no notable effect on the separation and preconcentration of $\mathrm{Cd}(\mathrm{II})$ and $\mathrm{Pb}(\mathrm{II})$ ions under the selected conditions (Table 2). Consequently, it can be concluded that the developed SPE method can be applied to the samples that consist of various foreign ions at allowable levels. 
Table 2: Influences of some foreign ions on the recoveries of analyte ions ( $N: 3$, sample $\mathrm{pH}: 6.5$, quantity of MFPTAHK: $8.0 \mathrm{mg})$.

\begin{tabular}{|l|c|c|c|c|}
\hline \multirow{2}{*}{ Ions } & \multirow{2}{*}{ Added as } & \multirow{2}{*}{ Conc.(mg L-1 } & \multicolumn{2}{|c|}{ Recovery (\%) } \\
\cline { 3 - 5 } & & & $\mathrm{Cd}(\mathrm{II})$ & $9 \mathrm{l}(\mathrm{II})$ \\
\hline $\mathrm{Na}^{+}$ & $\mathrm{NaCl}$ & 5000 & $90.3 \pm 2.7$ & $92.6 \pm 4.1$ \\
\hline $\mathrm{K}^{+}$ & $\mathrm{KCl}$ & 500 & $90.8 \pm 3.1$ & $91.2 \pm 3.3$ \\
\hline $\mathrm{Ca}^{2+}$ & $\mathrm{CaCl}_{2}$ & 500 & $96.3 \pm 2.7$ & $96.9 \pm 2.2$ \\
\hline $\mathrm{Mg}^{2+}$ & $\left.\mathrm{Mg}^{2+} \mathrm{NO}_{3}\right)_{2}$ & 1000 & $97.1 \pm 2.5$ & $90.3 \pm 2.7$ \\
\hline $\mathrm{CO}_{3}^{2-}$ & $\mathrm{Na}_{2} \mathrm{CO}_{3}$ & 1000 & $96.4 \pm 3.5$ & $95.3 \pm 4.6$ \\
\hline $\mathrm{SO}_{4}^{2-}$ & $\mathrm{Na}_{2} \mathrm{SO}_{4}$ & 1000 & $92.7 \pm 4.4$ & $90.8 \pm 3.3$ \\
\hline $\mathrm{NH}_{4}^{+}$ & $\mathrm{NH}_{4} \mathrm{NO}_{3}$ & 500 & $92.4 \pm 2.2$ & $91.9 \pm 3.8$ \\
\hline $\mathrm{PO}_{4}^{3-}$ & $\mathrm{Na}_{3} \mathrm{PO}_{4}$ & 1000 & $93.4 \pm 1.4$ & $97.4 \pm 1.1$ \\
\hline $\mathrm{Al}^{3+}, \mathrm{Mn}^{2+}, \mathrm{Ni}^{2+}, \mathrm{Co}^{2+}, \mathrm{Cu}^{2+}, \mathrm{Zn}^{2+}$ & $*$ & 25 & $90.5 \pm 1.9$ & $92.2 \pm 3.1$ \\
\hline $\mathrm{Mixed}^{2+}$ & & & $94.2 \pm 2.5$ & $91.2 \pm 3.9$ \\
\hline
\end{tabular}

*Added as nitrate salts

${ }^{\mathrm{a}} 5493 \mathrm{mg} \mathrm{L}{ }^{-1} \mathrm{Na}^{+}, 8390 \mathrm{mg} \mathrm{L}^{-1} \mathrm{Cl}^{-}, 2325 \mathrm{mg} \mathrm{L}^{-1} \mathrm{NO}_{3}^{-}, 250 \mathrm{mg} \mathrm{L}^{-1}, \mathrm{~K}^{+}, \mathrm{Ca}^{2+}, \mathrm{Mg}^{2+}, \mathrm{CO}_{3}{ }^{2-}, \mathrm{SO}_{4}^{2-}, \mathrm{PO}_{4}^{3-}, \mathrm{NH}_{4}^{+}, 10 \mathrm{mg} \mathrm{L}^{-1} \mathrm{Al}^{3+}, \mathrm{Mn}^{2+}, \mathrm{Ni}^{2+}, \mathrm{Co}^{2+}, \mathrm{Cu}^{2+}, \mathrm{Zn}^{2+}$

Table 3: Spiked recoveries of analyte ions from water samples ( $N: 3$, sample $\mathrm{pH}: 6.5$, sample volume: $50 \mathrm{~mL}$, final volume: $2.0 \mathrm{~mL}$ ).

\begin{tabular}{|c|c|c|c|c|c|}
\hline \multirow{2}{*}{ Element } & \multirow{2}{*}{ Added $(\mu \mathrm{g})$} & \multicolumn{2}{|c|}{ Sea water } & \multicolumn{2}{c|}{ Stream water } \\
\cline { 3 - 6 } & & Found $(\mu \mathrm{g})$ & Recovery $(\%)$ & Found $(\mu \mathrm{g})$ & Recovery $(\%)$ \\
\hline \multirow{3}{*}{$\mathrm{Cd}(\mathrm{II})$} & 0.0 & BDL* & - & BDL & - \\
\cline { 2 - 6 } & 5.0 & $4.60 \pm 0.11$ & 92.0 & $4.71 \pm 0.22$ & 94.2 \\
\cline { 2 - 6 } & 10.0 & $9.16 \pm 0.27$ & 91.6 & $9.47 \pm 0.49$ & 94.7 \\
\hline \multirow{3}{*}{$\mathrm{Pb}(\mathrm{II})$} & & & & & BDL \\
\cline { 2 - 6 } & 20.0 & $18.01 \pm 0.57$ & 90.0 & $19.20 \pm 0.44$ & 96.0 \\
\cline { 2 - 6 } & 40.0 & $36.94 \pm 1.35$ & 92.4 & $37.57 \pm 1.18$ & 93.9 \\
\hline
\end{tabular}

*Below detection limit

Table 4: Spiked recoveries of analyte ions from solid samples $(N: 3$, sample $\mathrm{pH}: 6.5$, sample quantities: $1.000 \mathrm{~g}$ of rice, cracked wheat and red lentil, final volume: $2.0 \mathrm{~mL}$ ).

\begin{tabular}{|c|c|c|c|c|c|c|c|}
\hline \multirow{2}{*}{ Element } & \multirow{2}{*}{ Added $(\mu \mathrm{g})$} & \multicolumn{2}{|c|}{ Rice } & \multicolumn{2}{c|}{ Cracked wheat } & \multicolumn{2}{c|}{ Red lentil } \\
\cline { 3 - 8 } & & Found $(\mu \mathrm{g})$ & Recovery $(\%)$ & Found $(\mu \mathrm{g})$ & Recovery $(\%)$ & Found $(\mu \mathrm{g})$ & Recovery $(\%)$ \\
\hline \multirow{3}{*}{$\mathrm{Cd}(\mathrm{II})$} & 0.0 & BDL & - & $0.11 \pm 0.02$ & - & BDL & - \\
\cline { 2 - 9 } & 5.0 & $4.72 \pm 0.23$ & 94.4 & $4.85 \pm 0.29$ & 94.8 & $4.72 \pm 0.37$ & 94.4 \\
\cline { 2 - 9 } & 10.0 & $9.60 \pm 0.30$ & 96.0 & $9.50 \pm 0.39$ & 93.9 & $9.59 \pm 0.43$ & 95.9 \\
\hline \multirow{3}{*}{$\mathrm{Pb}(\mathrm{II})$} & 0.0 & $1.16 \pm 0.12$ & - & BDL & - & BDL & - \\
\cline { 2 - 9 } & 20.0 & $19.86 \pm 2.26$ & 93.5 & $18.85 \pm 1.32$ & 94.2 & $18.51 \pm 0.85$ & 92.6 \\
\cline { 2 - 9 } & 40.0 & $38.14 \pm 1.57$ & 92.4 & $38.12 \pm 1.92$ & 95.3 & $36.50 \pm 1.97$ & 91.2 \\
\hline
\end{tabular}

Table 5: Analyte levels in real solid/liquid samples after being applied the presented SPE procedure $(N: 3$, sample quantities: $1.000 \mathrm{~g}$ of rice, cracked wheat and red lentil, final volumes: $2.0 \mathrm{~mL}$ ).

\begin{tabular}{|c|c|c|c|c|c|}
\hline \multirow{2}{*}{ Element } & \multicolumn{2}{|c|}{ Liquid samples $\left(\mu \mathrm{g} \mathrm{L}^{-1}\right)$} & \multicolumn{3}{c|}{ Solid samples $\left(\mu \mathrm{g} \mathrm{g}^{-1}\right)$} \\
\cline { 2 - 6 } & Sea water & Stream water $\left(\mu \mathrm{g} \mathrm{L}^{-1}\right)$ & Rice $\left(\mu \mathrm{g} \mathrm{g}^{-1}\right)$ & Cracked wheat $\left(\mu \mathrm{g} \mathrm{g}^{-1}\right)$ & ${\text { Red lentil }\left(\mu \mathrm{g} \mathrm{g}^{-1}\right)}^{\mathrm{Cd}(\mathrm{II})}$ \\
\hline $\mathrm{Pb}(\mathrm{II})$ & $5.32 \pm 0.11$ & $1.44 \pm 0.10$ & $\mathrm{BDL}$ & $0.11 \pm 0.02$ & BDL \\
\hline
\end{tabular}


Table 6: Comparative data from some recent studies on solid phase extraction.

\begin{tabular}{|c|c|c|c|c|c|c|}
\hline Analytes & SPE Adsorbent / Detection technique & PF & LOD $\left(\mu \mathrm{g} \mathrm{L}^{-1}\right)$ & RSD $(\%)$ & $\mathrm{pH}$ & Ref. \\
\hline $\mathrm{Cd}(\mathrm{II}), \mathrm{Pb}(\mathrm{II}), \mathrm{Cu}(\mathrm{II})$ & Amberlite XAD-2/FAAS & 50 & $0.8-23.2$ & $<5$ & 8.5 & 31 \\
\hline $\mathrm{Cd}(\mathrm{II}), \mathrm{Pb}(\mathrm{II})$ & Chromosorb-106/ AAS & 250 & $0.19-0.32$ & $<7$ & 9 & 32 \\
\hline $\mathrm{Cd}(\mathrm{II}), \mathrm{Pb}(\mathrm{II})$ & Colloidal sulfur/FAAS & 250 & $0.2-3.2$ & $<5.5$ & 8 & 33 \\
\hline $\mathrm{Cd}(\mathrm{II}), \mathrm{Pb}(\mathrm{II})$ & MWCNTs/P2AT nanocomposite/AAS & 280 & $0.3-1.0$ & $<3.5$ & 6 & 34 \\
\hline $\mathrm{Cd}(\mathrm{II}), \mathrm{Pb}(\mathrm{II})$ & Dowex Optipore V-493/FAAS & 50 & $0.43-0.65$ & $<5$ & 2 & 35 \\
\hline $\mathrm{Cd}(\mathrm{II}), \mathrm{Pb}(\mathrm{II})$ & Polyurethane foam/FAAS & 37 & $0.80-3.75$ & $<4.5$ & 7.5 & 35 \\
\hline $\mathrm{Cd}(\mathrm{II}), \mathrm{Pb}(\mathrm{II})$ & Amberlite XAD-8/FAAS & 50 & $0.31-0.86$ & $<4$ & 6.5 & Present work \\
\hline
\end{tabular}

SPE: Solid Phase Extraction; PF: Preconcentration Factor; LOD: Limit of Detection; RSD: Relative Standard Deviation

\section{Analytical figure of merits}

The precision of the method was determined by repeating the method for 10 times by using model solutions containing $2.0 \mu \mathrm{g}$ of $\mathrm{Cd}(\mathrm{II})$ and $10.0 \mu \mathrm{g}$ of $\mathrm{Pb}$ (II) ions under optimal conditions. Accordingly, the relative standard deviations (RSD) for $\mathrm{Cd}(\mathrm{II})$ and $\mathrm{Pb}(\mathrm{II})$ ions were found to be $3.7 \%$ and $3.1 \%$, respectively. The limit of detection (LOD) of the analyte ions, defined as the concentration that gives a signal equivalent to three times the standard deviation of 10 replicate measurements of the blank samples, was found to be $0.31 \mu \mathrm{g} \mathrm{L}^{-1}$ and $0.86 \mu \mathrm{g} \mathrm{L}^{-1}$, for $\mathrm{Cd}(\mathrm{II})$ and $\mathrm{Pb}$ (II) ions, respectively.

In order to check the accuracy of the SPE method, different amounts of the $\mathrm{Cd}(\mathrm{II})$ and $\mathrm{Pb}$ (II) ions were spiked in $50 \mathrm{~mL}$ of sea and stream water as liquid samples, and in $1.000 \mathrm{~g}$ of microwave digested rice, cracked wheat and red lentil as solid samples. As can be seen in Tables 3 and 4, good recoveries were obtained for $\mathrm{Cd}(\mathrm{II})$ and $\mathrm{Pb}(\mathrm{II})$ ions.

The method was applied to determine the analyte ions in real samples after being verified the accuracy of the method (Table 5).

\section{CONCLUSIONS}

The work in this dissertation investigated the use of a solid phase extraction technique in pre-concentration and separation of $\mathrm{Cd}(\mathrm{II})$ and $\mathrm{Pb}$ (II) ions in the presence of MFPTAHK onto Amberlite XAD-8 resin in a mini column. The procedure provides a sensitive, safe, rapid and simple enrichment of $\mathrm{Cd}(\mathrm{II})$ and $\mathrm{Pb}(\mathrm{II})$ ions in environmental food and water samples prior to the determination by FAAS with acceptable accuracy and precision. Various effective parameters that influence the preconcentration and separation of $\mathrm{Cd}$ (II) and $\mathrm{Pb}$ (II) ions were systematically studied and optimized to give over $95 \%$ recovery yield and the results obtained are discussed in this paper. The equilibrium data of Cd (II) and $\mathrm{Pb}$ (II) ions adsorption onto Amberlite XAD-8 resin were obtained with the Langmuir isotherm equation and the adsorption capacity of the Amberlite XAD-8 resin, without any lost of its physical-chemical features and adsorption properties, were evaluated as $3.76 \mathrm{mg} \mathrm{g}^{-1}$ and $5.07 \mathrm{mg} \mathrm{g}^{-1}$, respectively. The data obtained from the proposed method have been also compared with the previously reported SPE methods ${ }^{31-36}$ in terms of some optimization parameters (Table 6). The distinguished features of the present work are that the RSD and LOD values are relatively low, the working $\mathrm{pH}$ near to neutral and the preconcentration factor is relatively high when compared to other methods.

\section{REFERENCES}

1. F. M. El-demerdash, E. I. Elegamy, Int. J. Environ. Heal. R 9, 173, (1999)

2. J. Tapia, C. Bertrán, C. Araya, M. J. Astudillo, L. V. Chacoff, G. Carrasco, A. Vaderrama, L. Letelier, J. Chil. Chem. Soc. 54, 36, (2009)

3. A. Masotti, A. Giuliano, G. Ortaggi, Curr. Anal. Chem. 6, 37, (2010)

4. G. D. Matos, M. A. Z. Arruda, Spectrosc. Lett. 39, 755, (2006)

5. M. Z. Barciszewska, M. Szymanski, E. Wyszko, J. Pas, L. Rychlewski, J. Barciszewski, Mutat. Res. 589, 103, (2005)
6. M. Benomar, C. Mendiguchía, M. García-Vargas, C. A. Moreno, Spectrosc. Lett. 44, 83, (2011)

7. M. Karve, R. V. Rajgor, J. Hazard Mater. 141, 607, (2007)

8. M. I. Toral, N. Lara, J. Narváez, P. Richter, J. Chil. Chem. Soc. 49, 163, (2004)

9. H. Ince, S. Akman, U. Koklu, Fresenius. J. Anal. Chem. 342, 560, (1992)

10. J. S. Becker, TrAC Trend Anal. Chem. 24, 243, (2005)

11. N. Pourreza, K. Ghanemi, Spectrosc. Lett. 39, 127, (2006)

12. D. Afzali, N. Jandaghi, M. A. Taher, J. Chil. Chem. Soc. 56, 591, (2011)

13. M. Miro, J. M. Estela, V. Cerda, Curr. Anal. Chem. 1, 329, (2005)

14. S. Z. Mohammadi, M. A. Karimi, H. Hamidian, Y. M. Baghelani, L. Karimzadeh, J. Chil. Chem. Soc. 57, 1004, (2012)

15. E. B. Chubenko, A. A. Klyshko, V. P. Bondarenko, M. Balucani, Electrochimica Acta 56, 4031, (2011)

16. M. Ghaedi, A. Shokrollahi, R. Mehrnoosh, O. Hossaini, M. Soylak, Cent. Eur. J. Chem. 6, 488, (2008)

17. B. N. Kokare, A. M. Mandhare, M. A. Anuse, J. Chil. Chem. Soc. 55, 431, (2010)

18. G. M. Burke, R. W. Mendes, S. S. Jambhekar, Drug Dev. Ind. Pharm. 12, 713, (1986)

19. I. Narin, M. Soylak, Anal. Chim. Acta 493, 205, (2003)

20. C. Duran, A. Gundogdu, V. N. Bulut, M. Soylak, L. Elci, H. B. Senturk, M. Tufekci, J. Hazard. Mater. 146, 347, (2007)

21. P. K. Tewari, A. K. Singh, Talanta 56, 735, (2002)

22. G. Chakrapani, P. L. Mahanta, D. S. R. Murty, B. Gomathy, Talanta 53, $1139,(2001)$

23. K. O. Saygi, E. Melek, M. Tuzen, M. Soylak, Talanta 71, 1375, (2007)

24. P. Liu, Q. Pu, Z. Su, Analyst 125, 147, (2000)

25. E. A. Moawed, Anal. Chim. Acta 580, 263, (2006)

26. S. Doker, S. Malci, M. Dogan, B. Salih, Anal. Chim. Acta 553, 73, (2005)

27. M. Soylak, L. Elci, M. Dogan, J. Trace Microprobe T. 19, 329, (2001)

28. J. C. Lobartinia, K. H. Tana, L. E. Asmussena, R. A. Leonarda, D. Himmelsbacha, Commun. Soil Sci. Plan. 20, 1453, (1989)

29. H. Bayrak, A. Demirbas, S. A. Karaoglu, N. Demirbas, Eur. J. Med. Chem. 44, 1057, (2009)

30. H. B. Senturk, A. Gundogdu, V. N. Bulut, C. Duran, M. Soylak, L. Elci, M. Tufekci, J. Hazard. Mater. 149, 317, (2007)

31. P. Bermejo-Barrera, M.A. Nancy, D.L. Cristina, B.B. Adela, Microchim. Acta 142, 101, (2003)

32. M. Tuzen, K. Parlar, M. Soylak, J. Hazard. Mater. 121, 79, (2005)

33. H. Parham, N. Pourreza, N. Rahbar, J. Hazard. Mater. 163, 588, (2009)

34. M. R. Nabid, R. Sedghi, A. Bagheri, M. Behbahani, M. Taghizadeh, H. A. Oskooie, M. M. Heravi, J. Hazard. Mater. 203, 93, (2012)

35. E. Melek, M. Tuzen, M. Soylak, Anal. Chim. Acta 578, 213, (2006)

36. E.M. Gama, A.S. Lima, V.A. Lemos, J. Hazard. Mater. 136, 757, (2006) 